$\mathrm{T}$ аргетная терапия псориаза: ингибирование сигнального пути ИА-23 — Аанные клинических исследований и реальной практики

\author{
(C) Хотко А.А. ${ }^{1}$, Помазанова М.Ю. ${ }^{1}$, Круглова Л.С. ${ }^{2}$
}

\footnotetext{
${ }^{1}$ Государственное бюджетное учреждение здравоохранения «Клинический кожно-венерологический диспансер» Министерства здравоохранения Краснодарского края

350020, Россия, г. Краснодар, ул. Рашпилевская, д. 179

2 Федеральное государственное бюджетное учреждение дополнительного просрессионального образования «Центральная государственная медицинская академия» Управления делами Президента Российской Федерации

121359, Россия, г. Москва, ул. Маршала Тимошенко, д. 19, стр. 1 А
}

В статье представлены результаты клинических исследований эфффективности и безопасности применения нового препарата генно-инженерной биологической терапии гуселькумаба. Гуселькумаб является первым представителем класса ингибиторов ИЛ-23 и имеет ряд преимуществ перед существующей терапией. По данным прямых сравнительных рандомизированных клинических исследований, гуселькумаб превосходит по эффективности в краткосрочной и, что особенно важно, в долгосрочной перспективе большинство ГИБП, в том числе ингибиторы ФНО- $\alpha$, секукинумаб, устекинумаб. В исследованиях фразы 3 (VOYAGE 1 и VOYAGE 2), исследовании ECLIPSE показано, что гуселькумаб позволяет достичь полного (PASI 100) и почти полного (PASI 90) очищения кожи уже к 16-й неделе от начала терапии у 37,4 и 73,3\% пациентов соответственно, с последующим нарастанием доли пациентов с чистой и почти чистой кожей к 24-й неделе до 44,4 и 80,2\% соответственно и удержанием достигнутых показателей эфффективности в течение 4 лет на уровне у 51,7 и 84,0\% соответственно. Одним из потенциальных преимуществ ингибиторов ИЛ-23 также является длительное поддержание достигнутого эфрфекта после прекращения лечения. Терапия гуселькумабом характеризуется благоприятным профилем безопасности, сопоставимым с устекинумабом. В период наблюдения пациентов в ходе рандомизированных контролируемых исследований 3-й фразы были получены данные о высокой безопасности препарата и отсутствии существенных рисков в отношении серьезных инорекций, сердечно-сосудистых событий, злокачественных новообразований или суицидальных наклонностей. Препарат эффрективен при недостаточном ответе на адалимумаб и устекинумаб.

В статье представлены 3 клинических случая применения гуселькумаба у пациентов с тяжелым, в том числе «проблемным псориазом», коморбидной патологией, с неэффрективностью либо непереносимостью системной терапии, с вторичной неэффрективностью адалимумаба. У всех пациентов удалось достигнуть PASI 90/100. Нежелательные явления не отмечались.

Ключевые слова: вульгарный псориаз, интерлейкин-23, гуселькумаб, эффективность, PASI 90, PASI 100, коморбидные заболевания.

Конфрликт интересов: авторы заявляют об отсутствии потенциального конфрликта интересов, требующего раскрытия в данной статье.

Для цитирования: Хотко А.А., Помазанова М.Ю., Круглова Л.С. Таргетная терапия псориаза: ингибирование сигнального пути ИЛ-23 - данные клинических исследований и реальной практики. Вестник дерматологии и венерологии. 2020;96(4):49-59. doi: https://doi.org/10.25208/vdv1160-2020-96-4-49-59 


\title{
1 argeted therapy of psoriasis: inhibition of the IL-23 signaling pathway - evidence from clinical studies and real practice
}

\author{
(C) Alkes A. Hotko', Marina Yu. Pomazanova', Larisa S. Kruglova²
}

\author{
${ }^{1}$ State budgetary healthcare institution "Clinical dermatovenerologic dispensary» of the Ministry of healthcare of Krasnodar region \\ Rashpilevskaya str., 179, Krasnodar, 350020, Russia \\ ${ }^{2}$ FGBU "Central clinical hospital with polyclinic" Department of Presidential Affairs \\ Marshal Timoshenko str., 19, Moscow, 121359, Russia
}

The article presents the results of clinical studies of the efficacy and safety of the use of a new drug of genetically engineered biological therapy guselkumab. Guselkumab is the first representative of the interleukin-23 (IL-23) inhibitor class and has a number of advantages over existing therapy.

According to direct comparative randomized clinical trials, guselkumab is superior in the short-term and, most importantly, in the long-term to most genetically engineered biologic drugs, including TNF- $\alpha$ inhibitors, secukinumab and ustekinumab.

In phase 3 studies (VOYAGE 1 and VOYAGE 2), the ECLIPSE study shows that guselkumab can achieve complete (PASI 100) and almost complete (PASI 90) skin cleansing by 16 weeks from the start of therapy in 37.4 and $73.3 \%$ of patients, respectively, with a subsequent increase in the proportion of patients with clean and almost clean skin by 24 weeks to 44.4 and $80.2 \%$, respectively, and maintaining the achieved performance indicators for 4 years at the level of 51.7 and $84.0 \%$ respectively.

One of the potential advantages of IL-23 inhibitors is also the long-term maintenance of the achieved effect after treatment cessation. Guselkumab therapy is characterized by a favorable safety profile comparable to ustekinumab. During the follow-up period of patients in the course of randomized controlled trials of phase 3, data were obtained on the high safety of the drug and the absence of significant risks for serious infections, cardiovascular events, malignancies or suicidal tendencies. The drug is effective for insufficient response to adalimumab and ustekinumab.

The article presents 3 clinical cases of guselkumab use in patients with severe, including "problematic" psoriasis, comorbid pathology, with inefficiency or intolerance to systemic therapy, with secondary inefficiency of adalimumab. All patients managed to achieve a PASI of 90/100. No adverse events were observed.

Keywords: psoriasis vulgaris, interleukin-23, guselkumab, efficacy, PASI 90, PASI 100, comorbid disease.

Conflict of interest: the authors state that there is no potential conflict of interest requiring disclosure in this article.

For citation: Hotko AA, Pomazanova MYu, Kruglova LS. Targeted therapy of psoriasis: inhibition of the IL-23 signaling pathway - evidence from clinical studies and real practice. Vestnik Dermatologii i Venerologii. 2020;96(4):49-59. doi: https://doi.org/10.25208/vdv1160-2020-96-4-49-59 
Псориаз - хроническое иммуноопосредованное заболевание. Согласно современным клиникоэпидемиологическим данным псориазом страдает от 1 до 2\% населения планеты, при этом, по сведениям ВОЗ, в 2015 г. было зарегистрировано 125 млн больных псориазом [International Federation of Psoriasis Associations, 2015].

Причины развития псориаза сложны и определяются в первую очередь аберрантным иммунным ответом в коже, модифицируемым генетической восприимчивостью и различными стимулами (стресс, травма кожи, инфрекция и прием препаратов) [1]. Псориаз является управляемым цитокинами заболеванием. Установлено, что выраженная пролифрерация Т-лимфоцитов предшествует повышенной пролиферации кератиноцитов и акантозу, однако последующая миграция Т-клеток из дермы в эпидермис связана с гиперпролиферацией кератиноцитов [1, 2]. Дальнейшие доказательства важности интраэпидермальных Т-клеток были получены путем демонстрации того, что антитела к VLA-1 рецептору экспрессируются исключительно на интраэпидермальных Т-клетках [2, 3]. Иммуноопосредованные воспалительные реакции, связанные с псориазом, не ограничены только кожей, часто сопровождаются поражением суставов (псориатический артрит, ПА) и обуславливают растущее число сопутствующих коморбидных состояний, включая кардиоваскулярные заболевания, в том числе инсульт, метаболический синдром (ожирение, гипертензия, дислипидемия и сахарный диабет), хронические заболевания почек, заболевания органов ЖКТ, афффективные расстройства и злокачественные новообразования [2, 3].

Наиболее часто при псориазе гладкой кожи встречается псориатический артрит - до 40\% случаев [4]. Спектр локализаций воспаления при ПА достаточно велик, от осевого или периферического артрита до синовиального воспаления смежных мягких тканей, энтезита, остеитов, фрормирования тяжелых форм остеолиза, в ряде случаев эти симптомы сочетаются друг с другом [4].

В настоящее время в клинических рекомендациях по тактике ведения пациентов с псориазом рекомендуется проводить активный диагностический поиск ранних признаков ПА при осмотре каждого пациента. Если ПА уже диагностирован, выбор терапевтических мероприятий основывается на возможности влиять не только на кожные симптомы, но и на суставной синдром [5].

Арсенал методов, применяемых для лечения псориаза, включает местные и системные препараты, а также методы фризиотерапии. Выбор метода лечения зависит прежде всего от тяжести псориатического процесса, локализации поражения, значимых сопутствующих заболеваний (коморбидностей), эффрективности предыдущих методов и предпочтений пациента [6].

Согласно действующим в Российской Федерации клиническим рекомендациям РОДВК [Клинические рекомендации. Псориаз. 2020. Доступно на: http:// cr.rosminzdrav.ru/\#!/schema/866. Дата обращения: 23.07.2020], генно-инженерные биологические препараты (ГИБП) применяются:

при среднетяжелом и тяжелом бляшечном псориазе;

в случаях, если системные иммуносупрессоры или фототерапия оказываются недостаточно эффективными либо у пациента развивается непереносимость или имеются противопоказания к их применению.

В РФ зарегистрированы 4 класса ГИБП по показаниям бляшечный (вульгарный) псориаз: ингибиторы фрактора некроза опухоли (ФНО- $\alpha$ ), ингибиторы интерлейкина-17 (ИЛ-17), ингибитор интерлейкинов-12/23 (ИЛ-12/23), ингибитор интерлейкина-23 (ИЛ-23).

Представитель нового 4-го класса ГИБП гуселькумаб - это моноклональное человеческое антитело типа IgG1 $\lambda$, которое селективно связывается с белком интерлейкина-23 с высокой специфичностью и аффинностью. ИЛ-23 - это регуляторный цитокин, который влияет на диффференцировку, миграцию и жизнеспособность субпопуляций Т-клеток (например, Th17 и Tc17) и незрелых субпопуляций иммунных клеток, являющихся источником эфффекторных цитокинов, включая ИЛ17А, ИЛ-17F и ИЛ-22, участвующих в воспалительном каскаде. В исследованиях in vivo было показано, что селективная блокада ИЛ-23 нормализует выработку этих цитокинов. В присутствии ИЛ-23 повышается выживаемость Th17-лимфоцитов, продуцирующих ИЛ-17 и родственные ему цитокины. Кроме того, ИЛ-23 вызывает фенотипические и функциональные изменения Т-регуляторных клеток, способствующих повышению продукции воспалительных цитокинов: интерферона- $\gamma$, ФНО- $\alpha$, ИЛ-17А и ИЛ-22 [7, 8]. Поэтому ИЛ-23 считается ключевым цитокином в патогенезе псориаза. Это подтверждается его высоким содержанием как в сыворотке крови, так и в коже из псориатических очагов $[9,10]$. В исследованиях in vitro было показано, что гуселькумаб подавляет биологическую активность ИЛ-23 путем блокирования его взаимодействия с рецептором ИЛ-23 на поверхности клеток с последующим прерыванием опосредованных ИЛ-23 сигнальных, активирующих и цитокиновых каскадов. Клинические эффректы гуселькумаба при бляшечном псориазе связаны с блокадой сигнального пути ИЛ-23 [11, 12].

По данным клинических исследований гуселькумаб обладает рядом преимуществ: более высокой эффективностью в сравнении с ингибиторами ФНО- $\alpha$, секукинумабом и устекинумабом, долгосрочным, устойчивым ответом на терапию, благоприятным профилем безопасности и минимальной иммуногенностью [13-18].

Применение препарата гуселькумаб позволяет достичь полного (PASI 100), почти полного (PASI 90) очищения и PASI 75 уже к 16-й неделе от начала терапии у $37,4,73,3$ и 91,2\% пациентов соответственно, с последующим нарастанием доли пациентов с PASI 100/90/75 к 24-й неделе до 44,4, 80,2, 71,2\% соответственно и удержанием достигнутых показателей эффективности в течение 4 лет на уровне 55,7\% (49,1\% на 52-й неделе), 82,2\% (79,7\% на 52-й неделе), 94,1\% (93,8\% на 52-й неделе) терапии соответственно [16, 18]. Гуселькумаб продемонстрировал превосходящую эффективность у пациентов с тяжелым и среднетяжелым псориазом в сравнении с адалимумабом и устекинумабом, в том числе у больных с недостаточным ответом на терапию данными препаратами. В исследованиях 3-й фразы (VOYAGE 1 и VOYAGE 2) было показано, что гуселькумаб превосходит адалимумаб на 16 и 24-й неделях по количеству пациентов, достигших очищения кожи на 75, 90 и 100\% (PASI 75, PASI 90, PASI 100 соответственно), а также по влиянию на долю пациентов, достигших полного/почти полного очищения кожи, при использовании показателя Investigator Global Assessment (IGA), равного 0 или 1 баллу (IGA 0/1) [19]. Соответствующие показатели PASI 90 на 16-й неделе были достигнуты на гуселькумабе у 73,3\% по сравнению с 49,7\% пациентов из группы адалимумаба в VOYAGE 1 и 70,0\% 
по сравнению с 46,8\% пациентов из группы адалимумаба в VOYAGE 2 ( $p<0,001$ в обоих случаях) [16, 17].

В клинической практике одним из важных показателей эффективности применения ГИБП является интегративное понятие «выживаемость» терапии, включающее не только стойкое сохранение высоких показателей ответа PASI на протяжении длительного времени лечения, но и стабильное отсутствие побочных эффректов, осложнений терапии. Применение гуселькумаба обеспечивает длительный и стойкий эффект, так, достижение PASI 90 и PASI 100 на 1, 2, 3 и 4-м году терапии составляет 80,6, 83,3, 84,0, 84,3 и 49,7\%, 51,8, 51,8, $57,1 \%$ соответственно [20], что и определяет, среди прочего, высокую «выживаемость» гуселькумаба, приверженность как врачей, так и пациентов к продолжению терапии этим препаратом.

Еще одним актуальным вопросом является лечение псориаза определенных (т. Н. проблемных) локализаций (псориаз волосистой части головы, ладонно-подошвенный псориаз, инверсный, псориатическая ониходистрофия), что обусловлено торпидным течением, сложностями в выборе тактики ведения и выраженным отрицательным влиянием на качество жизни. Гуселькумаб достоверно превосходит адалимумаб в терапии «проблемного псориаза», демонстрируя устойчивый результат в течение года наблюдения $[16,18]$.

В прямом сравнительном исследовании эффективности и безопасности препаратов гуселькумаб и секукинумаб у пациентов с тяжелым и среднетяжелым псориазом было показано преимущество гуселькумаба в сравнении с секукинумабом в отношении доли пациентов, достигших PASI 90 к 48-й неделе терапии: 84,5 и 70,0\% пациентов соответственно $(p<0,001)$ [14].

С целью оценки сравнительной эфрфективности и безопасности гуселькумаба по сравнению с другими ГИБП в индукционном периоде (10-16 недель) был проведен систематический обзор и сетевой метаанализ [21]. Согласно результатам анализа 45 РКИ с включением 24515 пациентов гуселькумаб превосходит в эффективности адалимумаб, этанерцепт, инфоликсимаб, апремиласт, устекинумаб, тилдракизумаб и секукинумаб; препарат имеет благоприятное соотношение пользы и риска по сравнению с другими разрешенными к применению лекарственными средствами для лечения тяжелого и среднетяжелого псориаза. Следует отметить, что эффективность препарата не зависит от веса тела пациента [12].

«Эффрект ускользания», или вторичная неэффрективность ГИБП определяет смену тактики ведения пациентов, в том числе переключение на другой генноинженерный препарат. В клинической практике это достаточно сложная задача, которая прежде всего касается выбора последующего препарата. Решение может быть достигнуто, например, при переключении на ГИБП с иным механизмом действия. В исследовании VOYAGE 1 и 2 у 73\% пациентов, не достигших ответа на фоне 48-недельной терапии адалимумабом, отмечалось достижение ответа PASI 90 после переключения на терапию гуселькумабом [22]. В исследовании NAVIGATE прирост эфффективности у пациентов с недостаточным ответом на устекинумаб при переключении их на терапию гуселькумабом составил 27\% $(p<0,001)$ при оценке доли пациентов, достигших PASI 90 к 52-й неделе терапии $[12,13]$. Таким образом, данные клинических исследований позволяют рекомендовать гу- селькумаб в качестве препарата выбора при «эффректе ускользания» или недостаточной эффективности блокаторов иФНО-а, ИЛ-17 и ИЛ-12/23.

Гуселькумаб характеризуется низкой иммуногенностью. Доля пациентов, у которых развились антитела к препарату, составила 5,5\%, при этом не было отмечено влияния антител к препарату на показатели эффективности и безопасности проводимой терапии [12].

В клинических исследованиях гуселькумаб показал хороший профиль безопасности: менее $3 \%$ пациентов прекратили лечение из-за развития нежелательных явлений (НЯ) и менее 7\% пациентов испытали серьезные нежелательные явления (СНЯ). Наиболее частыми НЯ были инфекции. При этом в клинических исследованиях не сообщалось о развитии у пациентов, получавших гуселькумаб, оппортунистических инфекций, реактивации туберкулеза или реакций гиперчувствительности [11].

Одним из потенциальных преимуществ ингибиторов ИЛ-23 является длительное поддержание высокого уровня ответа после прекращения лечения. В популяционном исследовании ингибитор ИЛ-12/23 (устекинумаб) показал более высокую выживаемость терапии и более благоприятный профиль безопасности по сравнению с ингибиторами ИЛ-17 (секукинумаб, иксекизумаб) и ингибиторами ФНО- $\alpha$ (адалимумаб, этанерцепт, инфрликсимаб) и апремиластом [23].

В клинических исследованиях среднее время потери ответа PASI 90 на терапию гуселькумабом составило 23 недели. После последней инъекции гуселькумаба $36 \%$ пациентов сохраняют ответ PASI 90, 60\% пациентов - PASI 75 в течение 28 недель [17]. У $80 \%$ пациентов восстановление ответа PASI 90 отмечается уже после 3 введений гуселькумаба [24].

Псориаз нередко сочетается с системными коморбидными заболеваниями, включая метаболический синдром, ожирение, сахарный диабет II типа, ишемическую болезнь сердца, артериальную гипертензию, патологию гепатобилиарной системы, воспалительные заболевания кишечника [1, 2]. При этом основными целями терапии пациентов с псориазом являются не только достижение очищения кожи, повышение качества жизни пациентов, но и влияние на коморбидности, что невозможно без подбора наиболее безопасного генно-инженерного препарата, не имеющего ограничений при применении у пациентов с наиболее значимыми сопутствующими заболеваниями [1].

Анализ безопасности терапии гуселькумабом, по данным объединенного анализа исследований 3-й фразы VOYAGE 1, VOYAGE 2 [25], показал, что через 2 года лечения препаратом не было отмечено случаев активного туберкулеза, реактивации латентной туберкулезной инфекции (ЛТБИ) как в группах пациентов без ЛТБИ, так и в группе пациентов с ЛТБИ+. В то же время два новых случая активного туберкулеза произошли с применением адалимумаба у пациентов с ЛТБИ-. Среди пациентов с ЛТБИ+ демографические данные соответствовали эпидемиологии туберкулеза; ЛТБИ чаще всего встречалась у пациентов из Азиатско-Тихоокеанского региона. У 9 пациентов с ЛТБИ+, которые не следовали протоколу лечения и не получали противотуберкулезную терапию на фоне лечения гуселькумабом, не отмечалась активация туберкулезной инфекции. Лечение противотуберкулезными препаратами в сочетании с применением гуселькумаба было 
эфрфективным и безопасным в течение 2 лет терапии. Показатели повышенных АЛТ, АСТ чаще наблюдались у пациентов, получавших противотуберкулезные препараты, и скорее всего это не было связано с терапией гуселькумабом или адалимумабом. В целом результаты анализа показали, что гуселькумаб имеет хороший профиль безопасности. Механизм подавления ФНО- $\alpha$ затрагивает механизмы защиты от туберкулезной инфекции, в то время как механизм подавления ИЛ-23, вероятно, является безопасным и не вызывает активацию туберкулезной инфекции.

\section{Клинический случай № 1}

Пациент Ч., 1971 г.р., болеет псориазом в течение 13 лет. Лечился амбулаторно топическими ГК средствами с хорошим эфффектом. В сентябре 2014 г. отметил распространение высыпаний на кожу верхних и нижних конечностей, туловища, а также появление болей и припухание в области 2-го и 3-го пальцев левой стопы. По данным рентгенологического исследования выявлены признаки остеоартроза. Проконсультирован ревматологом, назначены нестероидные противовоспалительные препараты. В январе 2015 г. отмечалось ухудшение процесса, госпитализация в ГБУЗ ККВД с диагнозом: вульгарный псориаз, прогрессирующая стадия. Индекс PASI 23 балла. Псориатический артрит (1-2-й степени тяжести). Сопутствующие заболевания: гипертоническая болезнь, жировой гепатоз печени, дискинезия желче-

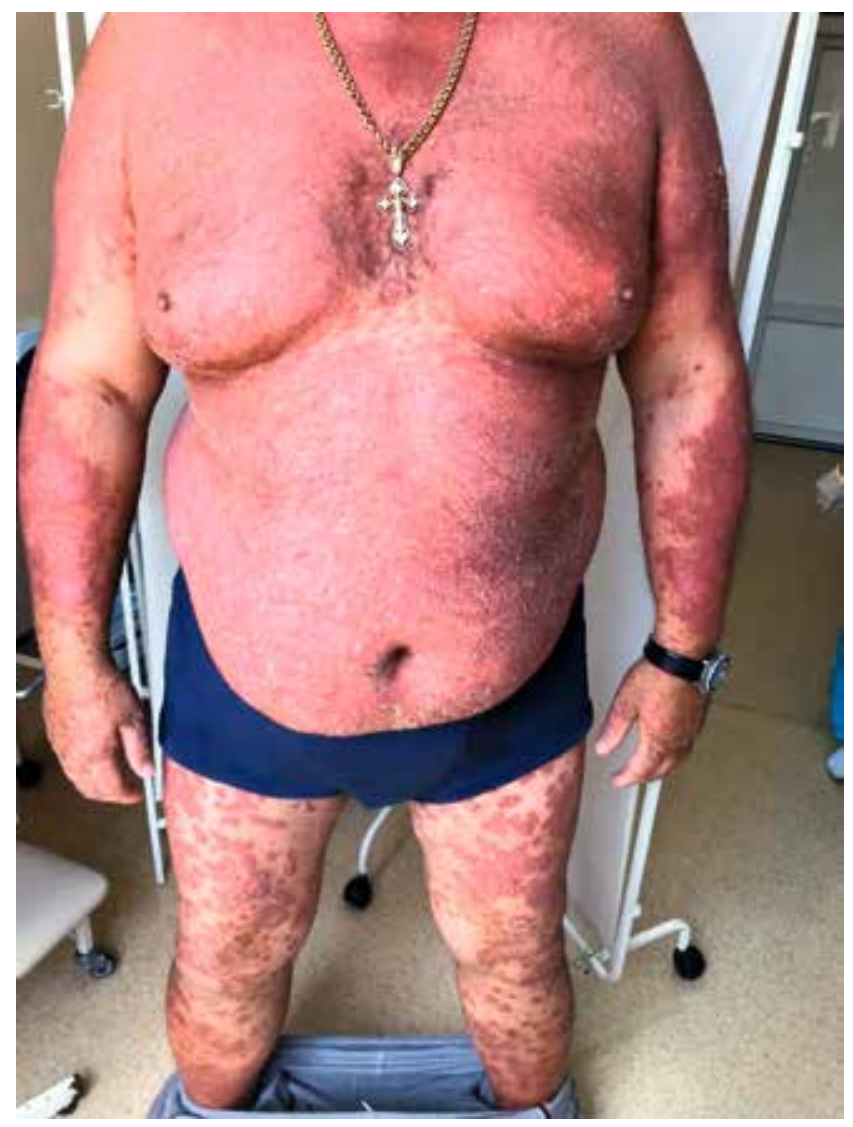

выводящих путей, ожирение 2-й степени. В анализе крови: повышение СОЭ до 40 мм в час, С-реактивный белок 52 мг/л. Назначено лечение метотрексатом в дозировке 20 мг 1 раз в неделю. После 2 месяцев приема метотрексата отмечались улучшение кожного процесса (PASI 50), уменьшение боли в суставах. Однако после 6 месяцев терапии отмечено повышение трансаминаз крови в 3 и более раза (АЛТ-10² E/л, АСТ 156 Е/л, ГГТ 235 Е/л), в связи с чем метотрексат был отменен. Учитывая распространенность кожного патологического процесса и появление болей и припухлости в области 4-го и 5-го пальцев правой стопы, пациенту был назначен препарат адалимумаб в дозировке 40 мг 1 раз в две недели. После 4-й инъекции пациент отмечал значительное улучшение кожного процесса, уменьшение болей в суставах, отсутствие припухлости. В анализе крови: СОЭ 20 мм в час, С-реактивный белок 10 мг/л, АЛТ-26 Е/л, АСТ 50 Е/л, ГГТ 42 Е/л. Констатировано достижение PASI 75.

Через 18 месяцев от начала приема препарата адалимумаб пациент отметил появление новых высыпаний, боли в области шейного отдела позвоночника. Был госпитализирован в стационарное отделение ГБУЗ ККВД. В анализе крови: СОЭ 45 мм в час, С-реактивный белок 50 мг/л. При осмотре: на коже волосистой части головы (затылочная область), туловища (грудь, спина, живот), верхних конечностей (разгибательные поверхности плеч, предплечий, локтевых суставов), нижних конечностей (передние и задние поверхности бедер, голеней,

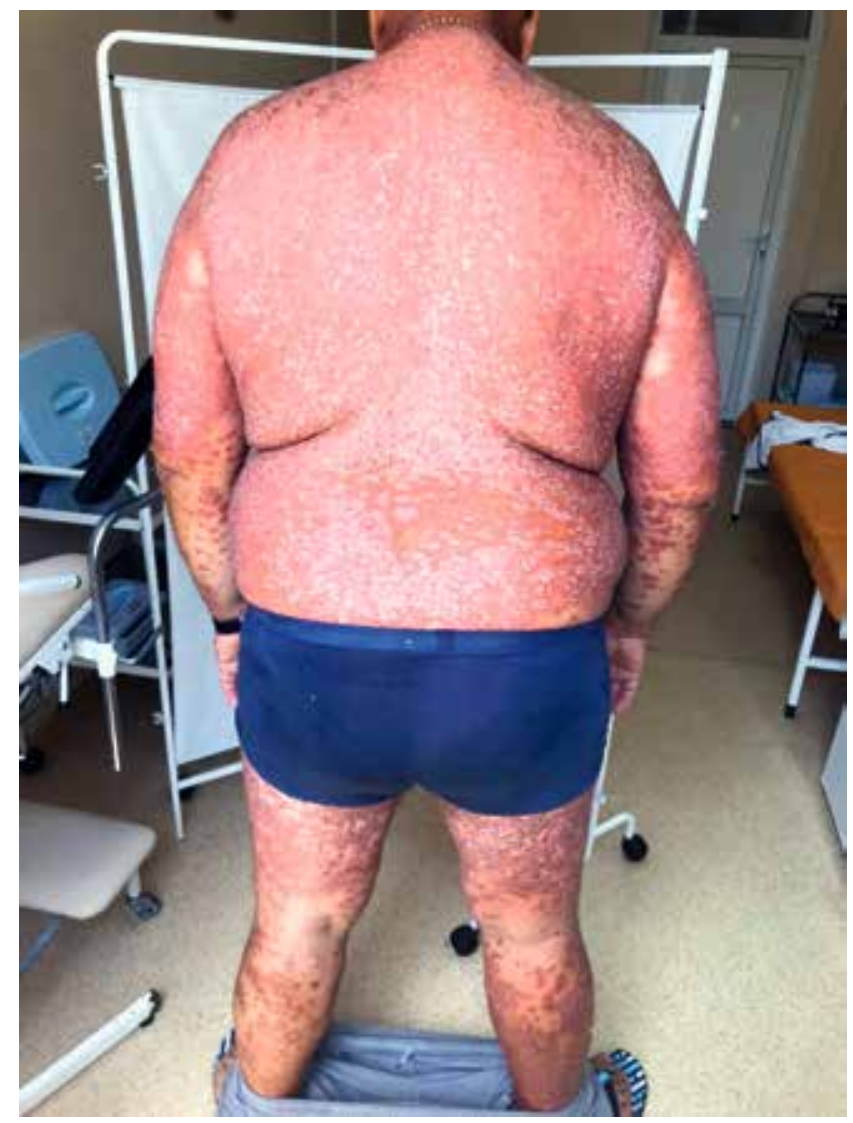

Pис. 1. Пациент Ч. до терапии
Fig. 1. Patient Ch. before therapy 

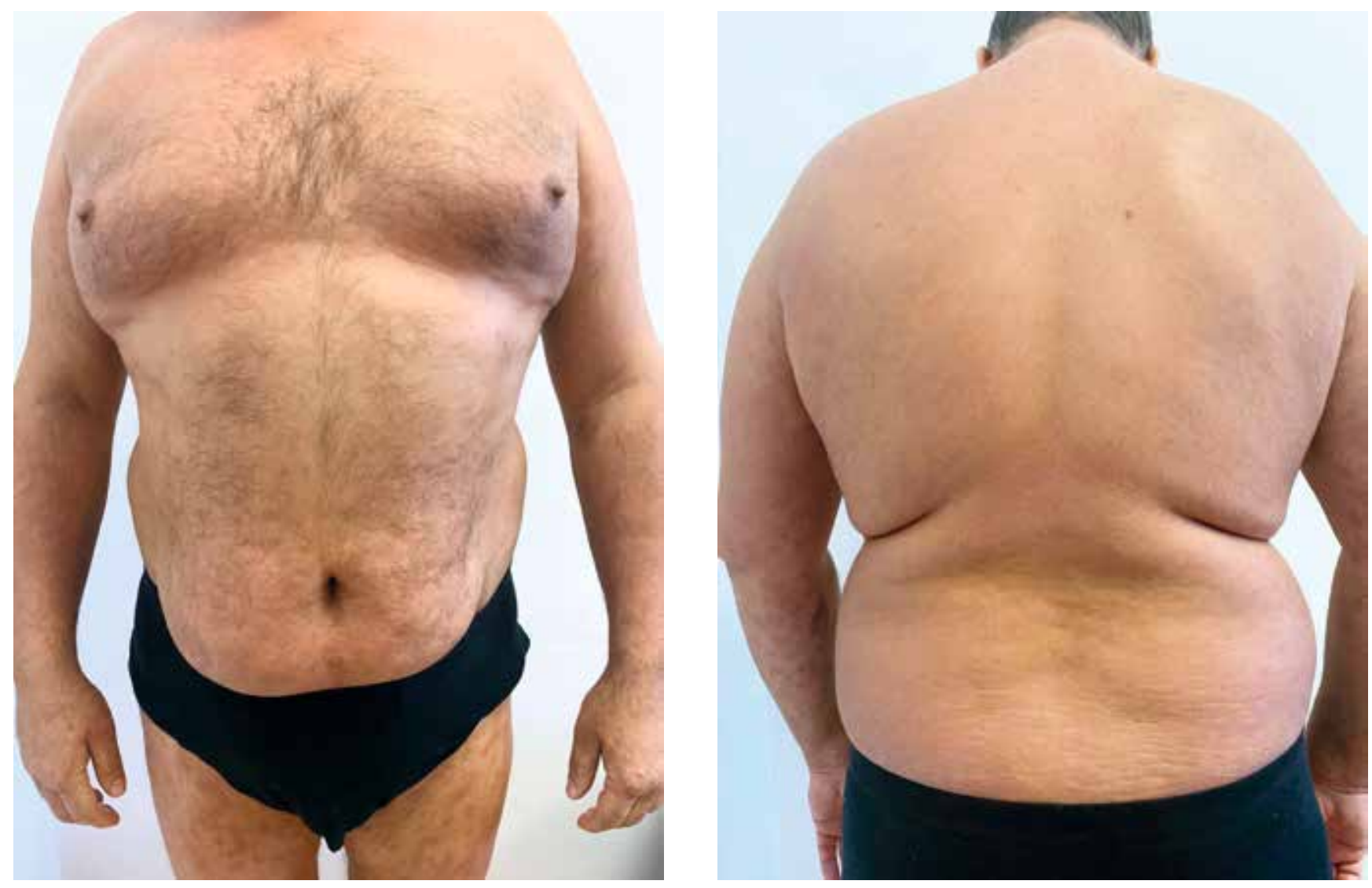

Pис. 2. Пациент Ч. после терапии гуселькумабом (20 недель), PASI 100
Fig. 2. Patient Ch. after therapy with guselkumab (20 weeks), PASI 100

разгибательные поверхности коленных суставов) множественные инфильтрированные бляшки ярко-красного цвета, покрытые частично прилегающими серебристыми чешуйками. Индекс PASI 46 баллов. Отмечается дефрормация мелких суставов кистей и стоп.

Учитывая прогрессирование кожного процесса, суставного синдрома на фроне приема препарата адалимумаб («эфрфект ускользания»), наличие у пациента сопутствующих соматических заболеваний, в том числе патологии печени, пациенту был назначен препарат гуселькумаб (Тремфея) в дозе 100 мг в виде п/к инъекций, вторая инъекция через 4 недели после первой, с последующими введениями 1 раз каждые 8 недель.

К 12-й неделе терапии гуселькумабом была отмечена выраженная положительная динамика: достижение PASI 90. После 4 инъекций был отмечен полный регресс высыпаний: достижение PASI 100. В клиническом анализе крови и в биохимическом анализе крови отклонений не выявлено. После 9 месяцев терапии ремиссия сохранялась, жалоб со стороны суставов нет.

\section{Клинический случай № 2}

Пациентка М., 1965 г.р., больна в течение 5 лет, когда после перенесенного стресса появились высыпания на коже волосистой части головы, верхних конечностей. Поставлен диагноз: вульгарный псориаз, прогрессирующая стадия, индекс PASI 26 баллов. Лечилась амбулаторно, периодически использовала ГКС мази. Во вре- мя очередного обострения в связи с тяжестью кожного процесса (PASI 28 баллов) был назначен метотрексат 15 мг п/к, 1 раз в неделю в течение полугода. После 8 инъекций отмечалось незначительное улучшение: индекс PASI составил 19 баллов. Далее кожный патологический процесс протекал без улучшений, в связи с чем метотрексат был отменен, обострение возникло через 3 месяца после отмены: индекс PASI 34 балла. Пациентка была госпитализирована в стационарное отделение ГБУЗ ККВД. При осмотре: на коже волосистой части головы, туловища (грудь, спина, живот), верхних конечностей (разгибательные поверхности плеч, предплечий), нижних конечностей (передние и задние поверхности бедер, голеней) множественные инфильтрированные по периферии папулы и бляшки ярко-красного цвета, покрытые частично прилегающими серебристыми чешуйками. В связи с неэффективностью применения метотрексата назначен препарат ацитретин 25 мг/сут, через 8 недель отмечено достижение PASI 75. На фоне приема ацитретина (6 месяцев) развились нежелательные явления: выраженная сухость кожи и слизистых, выпадение волос. Препарат был отменен. В ноябре 2019 г. - обострение кожного процесca: индекс PASI 31 балл. Сопутствующая соматическая патология: гипертоническая болезнь, сахарный диабет 2-го типа. Учитывая тяжесть, торпидность течения заболевания, отсутствие эффрективности от ранее проводимых методов системного лечения, наличие «псориа- 

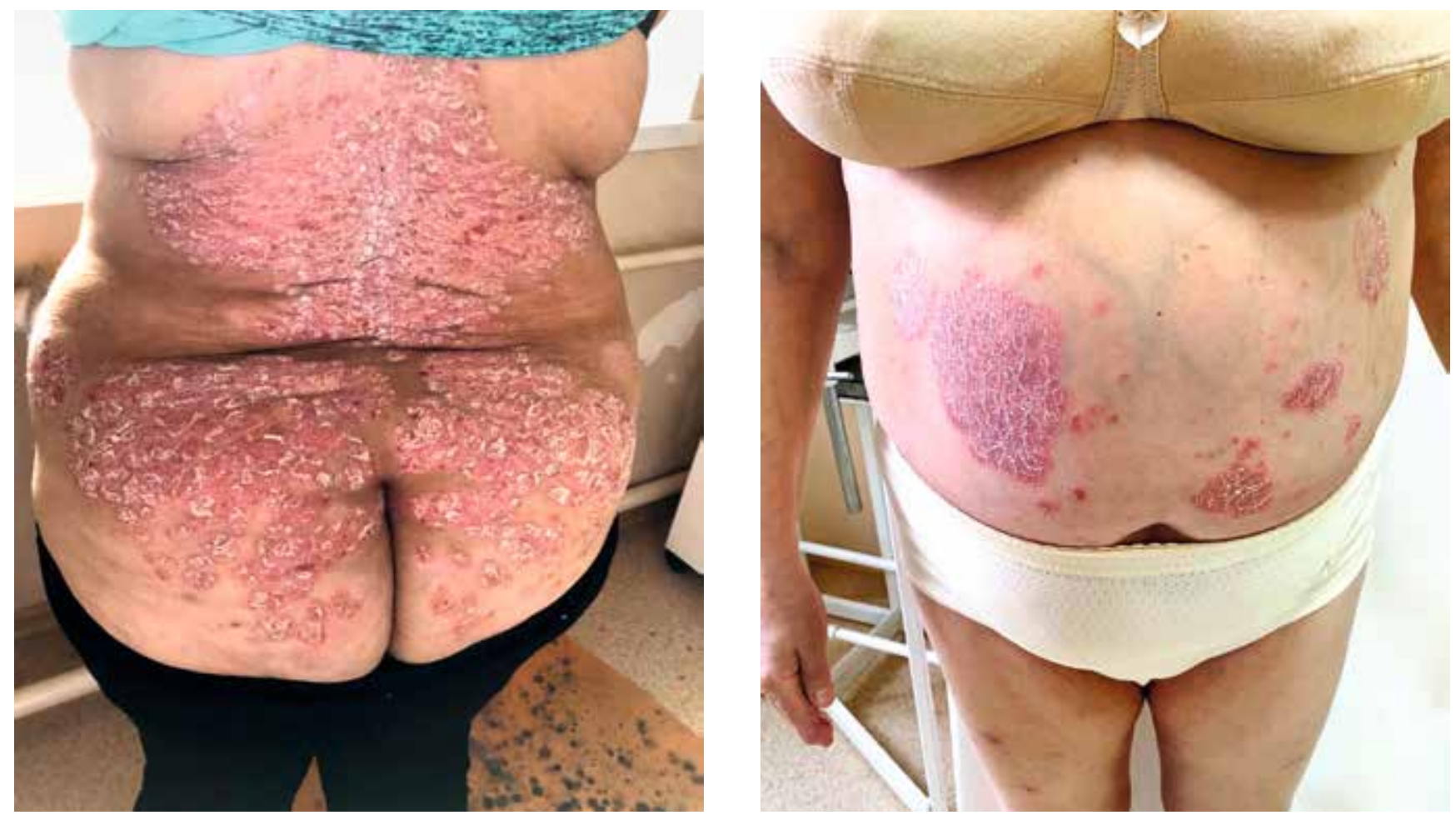

Рис. 3. Пациентка М. до терапии
Fig. 3. Patient M. before therapy


Pис. 4. Пациентка М. после терапии гуселькумабом (6 месяцев), PASI 90
Fig. 4. Patient M. after therapy with guselkumab (6 months), PASI 90 
за», рекомендована терапия препаратом гуселькумаб 100 мг по схеме. После необходимого стандартного обследования для исключения туберкулеза, гепатитов В и С проведена первая инъекция. После 2-й инъекции гуселькумаба отмечена положительная динамика: уменьшение папул, шелушения, инфильтрации, достижение PASI 50. После 6 месяцев лечения был отмечен регресс высыпаний, новых высыпаний нет, на месте разрешившихся элементов пятна вторичной гиперпигментации, отсутствие шелушения, достижение PASI 90. В клиническом анализе крови и в биохимическом анализе крови отклонений не выявлено.

\section{Клинический случай № 3}

Пациентка Б., 1958 г.р., болеет в течение 10 лет, когда впервые появились высыпания на коже верхних конечностей, туловища. К врачу не обращалась, лечилась самостоятельно народными средствами. В июне 2019 г. пациентка была госпитализирована в стационарное отделение ГБУЗ ККВД, был поставлен диагноз: вульгарный псориаз, прогрессирующая стадия. Индекс PASI 18 баллов. Псориатический артрит 2-й степени активности, с поражением перифрерических суставов (межфраланговых суставов кистей и стоп) ФН 1-2-й ст. Назначены дезинтоксикационная терапия, гипосенсибилизирующая терапия, гепатопротекторы, метотрексат 20 мг 1 раз в неделю, наружная терапия. СОЭ 50 мм/час, С-реактивный белок 58 мг/л. Остальные показатели в пределах нормы. Пациентка выписана с улучшением, индекс PASI 50. После 5-й инъекции метотрексата отметила появление новых высыпаний. К врачу не обращалась.



В январе 2020 г. пациентка была госпитализирована в стационарное отделение ГБУЗ ККВД в тяжелом состоянии. При осмотре: на коже волосистой части головы, лица, занимая всю анатомическую область, туловища (грудь, спина, живот), верхних конечностей (разгибательные поверхности плеч, предплечий), нижних конечностей (передние и задние поверхности бедер, голеней) множественные инфильтрированные папулы и бляшки ярко-красного цвета, склонные к слиянию, покрытые обильными серебристо-белыми чешуйками, боли в области суставов кистей и стоп. Со стороны суставов: жалобы на утреннюю скованность, боль в пятке при хождении, болезненность правого плечевого сустава. Проконсультирована ревматологом. Диагноз: вульгарный псориаз, тяжелая степень тяжести. Индекс PASI 40 баллов. Псориатический артрит. Сопутствующая соматическая патология: гипертоническая болезнь, аритмия, сахарный диабет 2-го типа, хронический гастрит, аутоиммунный тиреоидит. Лабораторные показатели: СОЭ 30 мм в час, С-реактивный белок 32 мг/л, АЛТ 80 Е/л, АСТ 110 Е/л, ГГТ 60 Е/л.

Учитывая прогрессирование кожного патологического процесса, после стандартного обследования пациентке был назначен гуселькумаб в дозе 100 мг в виде п/к инъекций по схеме.

Уже к 12-й неделе терапии гуселькумабом отмечена положительная динамика: уменьшение инфильтрации папул и бляшек, шелушения, констатировано достижение PASI 90. После 4 месяцев лечения был отмечен полный регресс высыпаний: PASI 100. В клиническом анализе крови и в биохимическом анализе крови отклонений не выявлено. После 6 месяцев терапии клиническая ремиссия сохраняется.

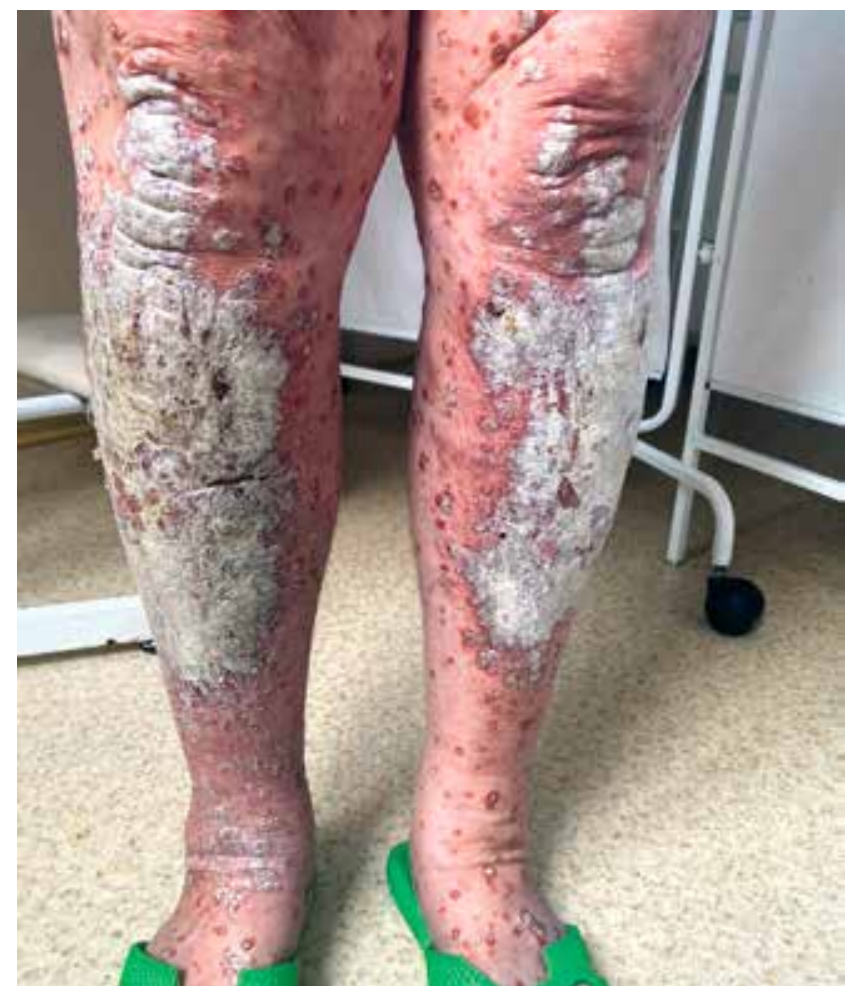

\footnotetext{
Pис. 5. Пациентка Б. до терапии
Fig. 5. Patient B. before therapy
} 

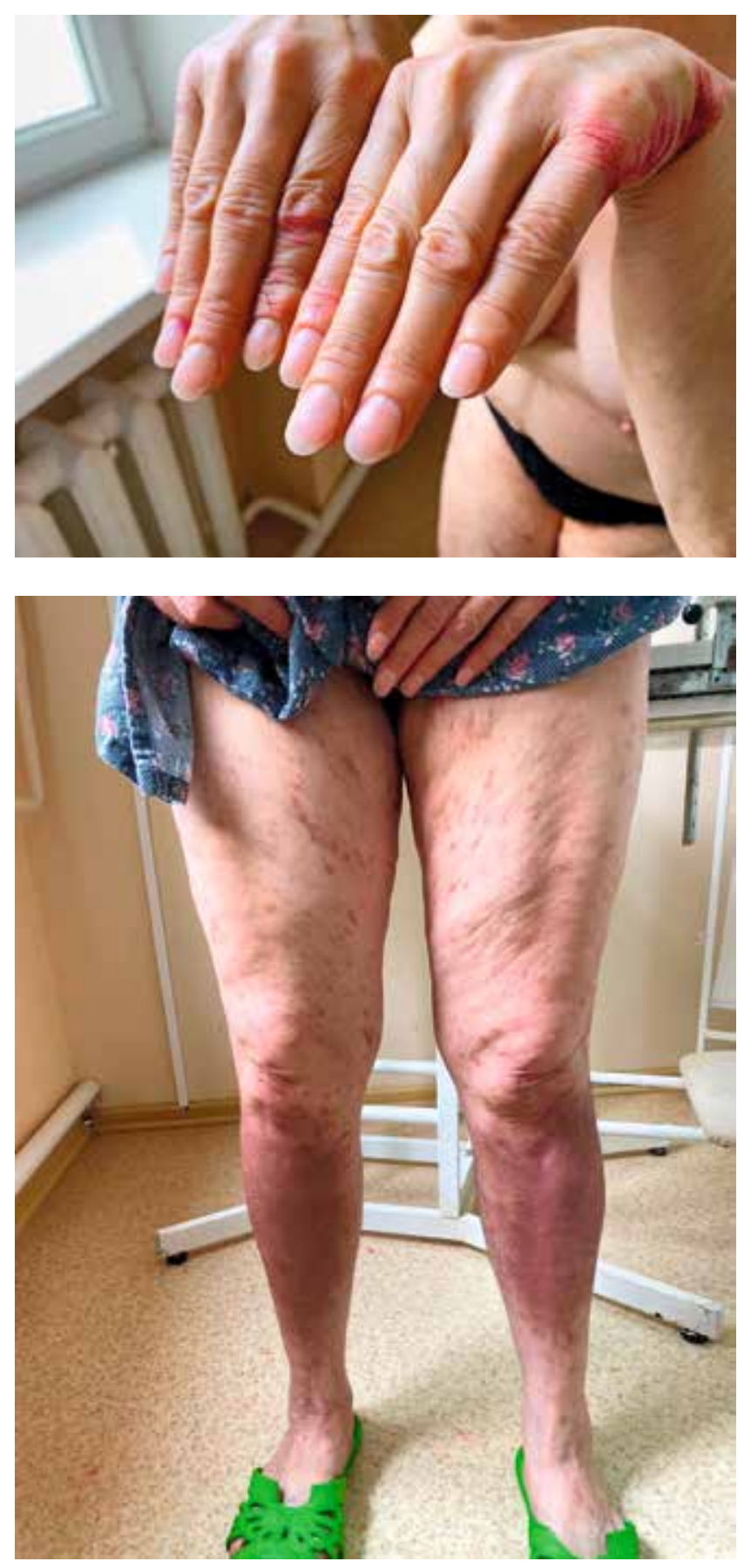

\section{Рис. 6. Пациентка Б. после терапии гуселькумабом (4 месяца), PASI 100 Fig. 6. Patient B. after therapy with guselkumab (4 months), PASI 100}

\section{Обсуждение результатов}

Препарат гуселькумаб активно внедряется в практику дерматовенерологов для лечения псориаза среднетяжелого и тяжелого течения. Особенно актуально использование данного препарата при «ускользании эфрфекта» от ранее проведенной генно-инженерной биологической терапии. Представленные клинические случаи демонстрируют высокую эффективность препарата гуселькумаб у пациентов с псориазом и псориатическим артритом как у био- наивных пациентов, так и у пациентов при неэфрфективности блокатора ФНО. Также клинические случаи демонстрируют высокую эффективность гуселькумаба в отношении достижения PASI 90 и PASI 100 у пациентов с тяжелым псориазом, в том числе в сочетании с ПА и сопутствующей коморбидной патологией. Лечение переносилось хорошо, нежелательных явлений в течение терапии не выявлено. Данные клинических исследований и практический опыт применения препарата определяют выбор гуселькумаба как препарата с лучшим на текущий период профилем эфрфективности, устойчивым профилем безопасности и возможностью применения у пациентов с сочетанной коморбидной патологией.

\section{Выводы}

Гуселькумаб является первым представителем класса ингибиторов ИЛ-23 и имеет ряд преимуществ перед существующей терапией. По данным метаанализа гуселькумаб превосходит по эффрективности в краткосрочной и, что особенно важно, в долгосрочной перспективе большинство ГИБП, в том числе ингибиторы ФНО- $\alpha$, секукинумаб, устекинумаб $[21,26]$.

Гуселькумаб эффрективен не только в отношении бляшечного псориаза, но и псориаза «проблемной» локализации (псориаз волосистой части головы, псориаз ладоней и подошв, псориатическая ониходистрофия), превосходя результаты применения адалимумаба. Благодаря своему механизму действия гуселькумаб практически лишен противопоказаний и особых указаний, связанных с использованием ингибиторов ФНО- $\alpha$ (сердечная недостаточность, аутоиммунное или демиелинизирующее заболевание) и ингибиторов ИЛ-17 (воспалительное заболевание кишечника, кандидоз слизистых оболочек и кожи) [17].

По данным клинических исследований гуселькумаб улучшает показатели качества жизни и трудоспособности, обладает благоприятным профилем безопасности. Терапия гуселькумабом характеризуется удобным режимом дозирования, а также низкими показателями иммуногенности и позволяет существенно повысить эфрфективность и переносимость проводимой терапии, в том числе у пациентов с недостаточным ответом на терапию адалимумабом и устекинумабом.

Гуселькумаб включен в российские клинические рекомендации РОДВК в 2020 г. по ведению больных псориазом [27]. Препарат показан следующим категориям пациентов: бляшечный псориаз средней и тяжелой степени тяжести с непрерывно рецидивирующим характером течения заболевания (частота госпитализаций в связи с обострением кожного процесса более 3 раз в год), выраженным нарушением качества жизни, при отсутствии эффекта или при плохой переносимости/наличии противопоказаний к применению системных противовоспалительных препаратов (метотрексат, ацитретин, циклоспорин или генно-инженерные биологические препараты) или угрозе утраты трудоспособности и инвалидизации. Отмечается эффективность гуселькумаба у пациентов с псориазом ногтей, волосистой части головы, ладонно-подошвенной области. Эфффективность препарата не зависит от веса пациентов.

Опыт применения гуселькумаба в реальной клинической практике показал его высокую эффективность 
у пациентов с тяжелым бляшечным псориазом, «проблемным» псориазом, в том числе в сочетании с ПА и другой коморбидной патологией. Долгосрочные данные клинического исследования VOYAGE 1 (204 недели) свидетельствуют об устойчивом поддержании высокого уровня ответа на препарат по показателям PASI 100, PASI 90, PASI 75, IGA 0, IGA 0/1 и, что не менее важно, показателей качества жизни пациентов, что может определять выбор препарата с учетом хронического, прогрессирующего характера течения заболевания.

\section{Литература/References}

1. Потекаев Н.Н., Круглова Л.С. Псориатическая болезнь. M., 2014;264 c. [Potekaev N.N., Kruglova L.S. Psoriatic disease. M., 2014;264 p. (In Russ).]

2. Abuabara K. Cause-specific mortality in patients with severe psoriasis: a population-based cohort study in the United Kingdom. Br J Dermatol. 2010;163(3):586-592.

3. Takeshita J, Grewal S, Langan SM, Mehta NN, Ogdie A, Van Voorhees AS, et al. Psoriasis and comorbid diseases: epidemiology. J Am Acad Dermatol. 2017;76:377-90.

4. Van de Kerkhof PC, Reich K, Kavanaugh A, Bachelez $H$, Barker J, Girolomoni G, Langley RG, Paul CF, Puig L, Lebwohl. Physician perspectives in the management of psoriasis and psoriatic arthritis: results from the population-based Multinational Assessment of Psoriasis and Psoriatic Arthritis survey. J Eur Acad Dermatol Venereol. 2015;29(10).

5. Насонов Е.Л. Ревматология: клинические рекомендации. М.: ГЭОТАР-Медиа. 2010;752 с. [Nasonov EL. Rheumatology: clinical guidelines. M.: GEOTAR-Media, 2010;752 p. (In Russ).]

6. Кубанова А.А. Иммунные механизмы псориаза. Новые стратегии биологической терапии // Вестник дерматологии и венерологии. 2010;№1:35-47. [Kubanova AA. Immune mechanisms of psoriasis. A new strategy for biological treatment // Vestnik of dermatology and venereology. 2010;№.1:35-47. (In Russ).]

7. Hawkes JE, Yan BY, Chan TC, Krueger JG. Discovery of the IL-23/IL-17 Signaling Pathway and the Treatment of Psoriasis. J Immunol. 2018;201(6):1605-1613.

8. Chan TC, Hawkes JE, Krueger JG. Interleukin 23 in the skin: role in psoriasis pathogenesis and selective interleukin 23 blockade as treatment. Ther Adv Chronic Dis. 2018;9(5):111-119.

9. Yang $L$, Li B, Dang E, et al. Impaired function of regulatory $T$ cells in patients with psoriasis is mediated by phosphorylation of STAT3. J Dermatol Sci. 2016;81(2):85-92.

10. Bovenschen HJ, van de Kerkhof PC, van Erp PE, et al. Foxp3+ regulatory $T$ cells of psoriasis patients easily differentiate into IL-17Aproducing cells and are found in lesional skin. J Invest Dermatol. 2011;131(9):1853-1860.

11. Puig L. Guselkumab for the treatment of adults with moderate to severe plaque psoriasis. Expert Rev Clin Immunol. 2019;15(6):589-597.

doi: 10.1080/1744666X.2019.1601014.

12. Инструкция по медицинскому применению гуселькумаба ЛП-005686 от 28.05.2020. [Электронный ресурс]. http://grls.rosminzdrav. ru (Дата обращения: 28.07.2020).

13. Langley RG, Tsai TF, Flavin S, et al. Efficacy and safety of guselkumab in patients with psoriasis who have an inadequate response to ustekinumab: results of the randomized, double-blind, phase III NAVIGATE trial. Br J Dermatol. 2018;178(1):114-123. doi:10.1111/bjd.15750.

14. Reich K, Armstrong April W, Langley Richard G, Flavin S, Randazzo B, Li S, Hsu Ming-Chun, Branigan P, Blauvelt A. Guselkumab versus secukinumab for the treatment of moderate-to-severe psoriasis (ECLIPSE): results from a phase 3, randomised controlled trial Lancet 2019;394:831-39.
15. Late Breaking [Электронный ресурс]. № 81201238. С. 1-9. URL: https://www.events.mondial.at/ei/2018/Downloads/Late_Breaking_Abstracts_1-8.pdf.

16. Blauvelt A, Papp KA, Griffiths CE, Randazzo B, Wasfi YS, Shen YK. Efficacy and safety of guselkumab, an anti-interleukin-23 monoclonal antibody, compared with adalimumab for the continuous treatment of patients with moderate to severe psoriasis: Results from the phase III, double-blinded, placebo- and active comparator. J. Am. Acad. Dermatol. Elsevier Inc, 2017;T.76:№3:P.405-417.

17. Reich K, Armstrong AW, Foley $P$, Song M, Wasfi YS, Randazzo B, Li SZ, Shen, Gordon K.B. Efficacy and safety of guselkumab, an anti-interleukin-23 monoclonal antibody, compared with adalimumab for the treatment of patients with moderate to severe psoriasis with randomized withdrawal and retreatment: Results from the phase III, double-blind, placebo- and active comparator-controlled VOYA. Journal of the American Academy of Dermatology. 2017;76:418-431.

18. Griffiths CEM, et al. Continuous treatment with guselkumab maintains clinical responses through 4 years in patients with moderate-to-severe psoriasis: results from VOYAGE 1. J Dermatolog Treat. 2020;Jul13;1-9. doi: 10.1080/09546634.2020.1782817. Online ahead of print.

19. Langley RG, Feldman SR, Nyirady J, van de Kerkhof P, Papavassilis $C$. The 5-point Investigator's Global Assessment (IGA) Scale: A modified tool for evaluating plaque psoriasis severity in clinical trials. J Dermatolog Treat. 2015;26(1):23-31. doi: 10.3109/09546634.2013.865009.

20. Griffiths CEM. Fall Clinical Dermatology Conference; October 1720,2019; Las Vegas, NV. www.mhra.gov.uk/yellowcard.

21. Cameron C, Druchok C, Hutton B, McElligott S, Nair S, Schubert A, Situ A, Varu A, Villacorta R. Guselkumab for the Treatment of Moderate-to-Severe Plaque Psoriasis During Induction Phase: A Systematic Review and Network Meta-Analysis. Journal of Psoriasis and Psoriatic Arthritis. 2019:4:81-92.

22. Griffiths CEM, Radtke MA, Youn SW, Bissonnette R, Song $M$, Wasfi Y, Randazzo B, You Y, Shen Y-K, Strober B. Clinical response after guselkumab treatment among adalimumab PASI 90 nonresponders: Results from the VOYAGE 1 and 2 trials. Journal of the American Academy of Dermatology, Volume 79 , Issue $3, \mathrm{AB} 78$.

23. Lunder T, Puig L, Tsai TF, Bhutani T, Ramachandran P, Uy J, Song M, You Y, Gooderham M, Lebwohl M. Drug survival of biological therapy is showing class effect: updated results from Slovenian National Registry of psoriasis. Int. J. Dermatol. 2019. C. ijd.14429.

24. Gordon KB, Armstrong AW, Foley $P$, et al. Guselkumab Efficacy after Withdrawal Is Associated with Suppression of Serum IL-23-Regulated IL-17 and IL-22 in Psoriasis: VOYAGE 2 Study. J Invest Dermatol. 2019;139(12):2437-2446.e1. doi: 10.1016/j.jid.2019.05.016.

25. Puig L, Tsai TF, Bhutani T, Ramachandran P, Uy J, Song M, You Y, Gooderham M, Lebwohl M. Safety in moderate-to-severe plaque psoriasis patients with latent tuberculosis treated with guselkumab and antituberculosis treatments concomitantly: results from pooled phase 3 VOYAGE 1 \& VOYAGE 2 trials Eur Acad Dermatol Venereol 2020 Apr 14. doi: 10.1111/jdv.16460. 
26. Armstrong April W, Puig L, Joshi A, et al. Comparison of Biologics and Oral Treatments for Plaque Psoriasis: A Meta-analysis. JAMA Dermatol. 2020;156(3):258-269. doi: 10.1001/jamadermatol.2019.4029
27. Клинические рекомендации. Псориаз. 2020. Доступно на: http://cr.rosminzdrav.ru/\#!/schema/866 (Дата обращения: 23.07.2020). [Clinical guidelines. Psoriasis. 2020. Available at: http://cr.rosminzdrav. ru/\#!/schema/866 (Date accessed: 23.07.2020) (In Russ).]

\section{Инсормация об авторах}

Алкес Асланчериевич Хотко - к.м.Н., заместитель главного врача по медицинской части, Государственное бюджетное учреждение здравоохранения «Клинический кожно-венерологический диспансер» Министерства здравоохранения Краснодарского края; e-mail: alkes@inbox.ru; ORCID iD: https://orcid.org/0000-0002-8688-4876

Марина Юрьевна Помазанова - заведующая женским стационарным отделением, Государственное бюджетное учреждение здравоохранения «Клинический кожно-венерологический диспансер» Министерства здравоохранения Краснодарского края; e-mail: mmm-marusyammm@mail.ru; ORCID iD: https://orcid.org/0000-0003-0122-5319

Лариса Сергеевна Круглова - д.м.н., проректор по учебной работе, заведующий кафедрой дерматовенерологии и косметологии Федерального государственного бюджетного учреждения дополнительного профрессионального образования «Центральная государственная медицинская академия» Управления делами Президента Российской Федерации; e-mail: kruglovals@mail.ru; ORCID iD: https://orcid.org/0000-00025044-5265

\section{Information about the authors}

Alkes A. Hotko - Cand. Sci. (Med.), Deputy Chief Physician for General Medicine State budgetary Healthcare institution "Clinical dermatovenerologic dispensary» of the Ministry of healthcare of Krasnodar region; e-mail: alkes@inbox.ru; ORCID iD: https://orcid.org/0000-0002-8688-4876

Marina Yu. Pomazanova - Dermatovenerologist, Head of the female in patient department State budgetary Healthcare institution "Clinical dermatovenerologic dispensary» of the Ministry of healthcare of Krasnodar region; e-mail: mmm-marusya-mmm@mail.ru; ORCID iD: https://orcid.org/0000-0003-0122-5319

Larisa S. Kruglova - Dr. Sci. (Med.), Prof., Departmental Head, Department of the Dermatovenereology and Cosmetology, Central State Medical Academy of Affairs Management Department of President of Russian Federation; e-mail: kruglovals@mail.ru; ORCID iD: https://orcid.org/0000-0002-5044-5265

Статья поступила в редакцию: 18.08 .2020

Принята к публикации: 07.09.2020

Дата публикации: 12.11.2020
Submitted: 18.08 .2020

Accepted: 07.09 .2020

Published: 12.11 .2020 